\title{
Genome Comparison of Pseudomonas fluorescens UM270 with Related Fluorescent Strains Unveils Genes Involved in Rhizosphere Competence and Colonization
}

\author{
Julie E. Hernández-Salmerón1, Gabriel Moreno-Hagelsieb² and Gustavo Santoyo ${ }^{1 凶}$ \\ 1. Instituto de Investigaciones Químico Biológicas, Universidad Michoacana de San Nicolás de Hidalgo, Morelia, Michoacán, México; \\ 2. Department of Biology, Wilfrid Laurier University, Waterloo, Ontario, Canada.
}

\begin{abstract}
$\square$ Corresponding author: Gustavo Santoyo, gsantoyo@umich.mx
( ) Ivyspring International Publisher. This is an open access article distributed under the terms of the Creative Commons Attribution (CC BY-NC) license (https://creativecommons.org/licenses/by-nc/4.0/). See http://ivyspring.com/terms for full terms and conditions.
\end{abstract}

Received: 2017.06.22; Accepted: 2017.08.18; Published: 2017.08.24

\begin{abstract}
Pseudomonas fluorescens UM270 is a rhizosphere-colonizing bacterium that produces multiple diffusible and volatile compounds involved in plant growth-promoting activities. Strain UM270 exhibits excellent biocontrol capacities against diverse fungal pathogens. In a previous study, the general UM270 genome characteristics were published. Here, we report a deeper analysis of its gene content and compare it to other $P$. fluorescens strains to unveil the genetic elements that might explain UM270's great colonizing and plant growth-promoting capabilities. Our analyses found high variation in genome size and gene content among the eight Pseudomonas genomes analyzed (strains UM270, Pf0-1, A506, F113, SBW25, PICF-7, UK4 and UW4). A core genome of 3,039 coding DNA sequences (CDSs) was determined, with 599 CDSs present only in the UM270 genome. From these unique UM270 genes, a set of 192 CDSs was found to be involved in signaling, rhizosphere colonization and competence, highlighted as important traits to achieve an effective biocontrol and plant growth promotion.
\end{abstract}

Key words: Pseudomonas, Comparative Genomics, Rhizosphere, Biocontrol, Plant Growth-Promotion Bacteria.

\section{Introduction}

The gram-negatives bacteria classified into the genus Pseudomonas comprise a great variety of microorganisms inhabiting diverse ecological niches. These bacteria can be found as human pathogens (1), as free-living organisms in water and soil, and, mainly, associated to the plant rhizosphere and endosphere (2). Thus, showing versatile lifestyles and varied metabolisms, which help to respond well to a wide variety of biotic and abiotic factors (3).

Particularly, P. fluorescens strains are common inhabitants of the plant rhizosphere and some strains actively colonize the internal plant tissues, living as endophytes (4), where they play diverse beneficial activities. P. fluorescens strains also exhibit different mechanisms, either direct or indirect, that promote plant growth and/or biological control against fungi and other pathogens (5). The main mechanisms attributed for biocontrol include: synthesis of secondary metabolites, such as 2,4-diacetylphloroglucinol (2,4-DAPG), hydrogen cyanide $(\mathrm{HCN})$, pyoluteorin, pyrrolnitrin, phenazines, cyclic lipopeptides (CLP) and siderophores (6); production of phytohormones, such as auxins, cytokinins and gibberellins; as well as nutrient solubilization traits (nitrogen, phosphorous, iron), which directly favors plant growth and health (7).

Few complete genomic sequence comparisons of Pseudomonas species have been previously reported 
(8-10). Such comparisons have been relevant to discover important genomic differences among species or strains. For example, Feil et al. (2005) compared the genome sequences of Pseudomonas syringae pv. syringae $\mathrm{B} 728 \mathrm{a}$ and $P$. syringae $\mathrm{pv}$. tomato DC3000, two economically important pathovars species of plant pathogenic bacteria. Such comparison revealed diverse unique genes in strain B728a. For example, functions such as ectoine synthase, DNA repair, and antibiotic production, were discovered to be involved in the epiphytic fitness and stress tolerance (8).

A genomic comparison of fluorescent genomes (strains SBW25, Pf0-1, Pf-5) (9) revealed a huge genomic heterogeneity among the three strains analyzed, and that the $42 \%$ of plant-inducible genes were not shared by all fluorescent strains, suggesting that ecological success requires specialized and core functions. In addition, the core genome and pangenome of twelve $P$. aeruginosa strains was reported (10), as well as the accessory genome of these species that ranged from $6.9-18.0 \%$ of the total genome, with most of these accessory genes found in mobile elements, and a majority of them with unknown or unclear function.

P. fluorescens UM270 was isolated from the rhizosphere of Medicago spp. plants. The strain revealed different plant growth-promoting activities, in addition to great rhizosphere-colonizing and competence traits (11). A draft genome sequence was recently reported due to the interest in identifying the genetic determinants responsible for its plant benefiting capacities (12). This work presents a genomic analysis of the UM270 gene functions as compared to other available pseudomonad genomes, highlighting the genetic and functional differences between each strain of this group of fluorescent and plant growth-promoting bacteria.

\section{Methods}

\section{Genomic comparison}

Comparison of eight Pseudomonas fluorescens genomes, including the strains A506 (2), Pf0-1, SBW25 (9), F113 (13), PICF7 (14), UK4 (15), as well as the UM270 strain, was carried out. Though Pseudomonas sp. UW4 has not been confirmed as a P. fluorescens species (16), it is still closely related to the fluorescent group, and was included in the analysis. Complete genome sequence traits are described for the eight strains analyzed here (Table 1). Original genome annotations were obtained directly from the NCBI nucleotide database. Genomic comparison were made using Mega 5 (17). Previous to the analysis, all homologous sequences were identified by comparing all the protein sequences using the Ublast algorithm, contained in USEARCH (18), against NCBI's non-redundant database (nr), with an e-value threshold of 1e-6. The SEED database was used to associate orthologous functions between the pseudomonad genomes.

\section{Core-genome analysis}

The core genome of eight $P$. fluorescens strains and Pseudomonas sp. UW4 was calculated by pairwise comparison using Reciprocal Best Hits (RBH) (19). Briefly, all eight strains were compared against each other using blastp with an e-value threshold of 1e-6, and then we searched for orthologs as RBH. All genes were combined into a single file and all genes conserved among the genomes were counted, and all "unique" genes were also counted for each genome. Here we refer to "unique" genes as those found in only one of the genomes analyzed, even if they might be present in some pseudomonad strains outside of this study. A literature search of the assigned functions in all genes found to be unique to the strain UM270 was performed.

Table 1. Genomic features of Pseudomonas strains analyzed in this work.

\begin{tabular}{|c|c|c|c|c|c|c|c|c|}
\hline Strain & Size (bp) & Plasmids & GC $\%$ & CDS & rRNA & Origin & Role & Reference \\
\hline UM270 & $6,050,830$ & - & 60.6 & 5,396 & 114 & Alfalfa rhizosphere & PGPB, biocontrol & $(12)$ \\
\hline A506 & $5,962,570$ & 1 & 60 & 5,267 & 87 & Pear phyllosphere & Biocontrol & $(2)$ \\
\hline PF0-1 & $6,438,405$ & - & 60.62 & 5,741 & 92 & Soil & Soil commen-sal & (9) \\
\hline SBW25 & $6,722,539$ & - & 60.5 & 6,009 & 82 & Sugar-beet phyllosphere & PGPB & (9) \\
\hline F113 & $6,845,832$ & - & 60.8 & 5,862 & 81 & Sugar-beet rhizosphere & Biocontrol & (13) \\
\hline PICF7 & $6,136,735$ & - & 60.4 & 5,567 & 88 & Olive endosphere & PGPB, biocontrol & $(14)$ \\
\hline UK4 & $6,064,456$ & - & 60.1 & 5,178 & 86 & Water biofilm & Amyloid- producing & (15) \\
\hline UW4 & $6,183,388$ & - & 60.05 & 5,423 & 94 & Reeds rhizosphere & PGPB & $(16)$ \\
\hline
\end{tabular}




\section{Results and Discussion}

\section{Genomic features of the strains}

A total of eight complete genomes of $P$. fluorescens (and Pseudomonas sp. UW4) were downloaded from GenBank and compared against the recently sequenced strain UM270 (12) (Table 1). All genomes consisted of a single circular chromosome, except for A506, which is the only genome containing a plasmid (2). In agreement with previous reports on Pseudomonas spp. (2), these genomes varied in genome size from $5.9-6.8 \mathrm{Mb}$, and the number of CDSs ranged from 5,178 to 6,009. Most of the strains are plant-associated, and were isolated from rhizosphere, endosphere and phyllosphere, except for strain UK4, which was isolated from a biofilm, formed on a drinking water fountain (Table 1). There is no evidence that the latter strain has a plant-associated role, but was included as an out-group.

\section{Comparative genomics of UM270 with fluorescent Pseudomonas}

A general comparison of genomic functions among Pseudomonas strains, shows similar abundance of genes involved in primary metabolism, such as pathways for amino acid synthesis, carbohydrate metabolism, proteins and DNA processing, were found. Virulence, disease and defense are common activities among these strains, similarly to metabolism of potassium, phosphorus, sulfur and iron (Supplementary Figure 1). Several functions vary among the members of this group of bacteria, such as metabolism of nitrogen, respiration, cell wall and capsule, stress response, secondary metabolite biosynthesis, regulation and cell signaling; this variation in gene functions could help us understand the ability of colonization and adaptability of these rhizosphere-colonizing bacteria. Interestingly, $P$. fluorescens F113 and UM270 displayed the major abundance of functions involved in motility and chemotaxis.

A closer comparative analysis was performed for the presence/absence of functions involved in biocontrol and the interactions of $P$. fluorescens strains with plants and the environment. Biological control mechanisms include synthesis of secondary metabolites against bacterial and fungal pathogens, including toxins and bacteriocins. The UM270 genome contains biosynthetic genes for multiple secondary metabolites, such as 2,4-DAPG, phenazines and $\mathrm{HCN}$; the rest of genomes contained only one or two of these functions. These secondary metabolites are probably responsible for UM270 being an efficient biological control agent. Unlike UM270, strains PICF-7 and PfO-1 exhibited chitinase activity, an important trait for fungal cell wall degradation. The presence of biosynthetic genes for bacteriocins is common to all genomes, except for microcin in UM270.

Siderophores are very important for a plant growth-promoting bacteria (PGPB), since they fulfill relevant activities in the rhizosphere to promote plant growth and control phytopathogens $(20,21)$. PGPB can excrete high-affinity siderophores to chelate $\mathrm{Fe}[\mathrm{III}]$ from bulk or rhizospheric soil and thereby making it available for the bacteria and plant cells; but at the same time, making it less available for the phytopathogens, thus preventing plant diseases (22). In this regard, pyoverdine is a common trait of the $P$. fluorescens strains, but several other siderophores were found in the strains analyzed here, such as achromobactin, enterobactin, pseudomonin, rhizobactin and piochelin.

Communication between bacteria and the plant host involve important signaling molecules. Among these, phytohormones play a crucial role in such interaction. UM270 was the only strain possessing genes involved in the synthesis of indole-3-acetic acid (IAA), the most common auxin, and phenylacetic acid (PAA), also known for its antimicrobial activity (23). The IAA synthesis in UM270 strain by Hernández-León et al. (2015) has been previously detected (11).

The presence of the acdS gene, encoding an 1-aminocyclopropane-1-carboxylic acid (ACC) deaminase was detected in all the genomes analyzed here, which highlights the relevant role of this enzyme in lowering the levels of ethylene, thus indirectly promoting plant growth (24).

An important gene involved in the synthesis of the volatile organic compound 2,3-butanediol was found in strains UM270 and F113. This volatile has been associated with the induction of systemic resistance in Arabidopsis thaliana and tobacco plants. Importantly, bacterial mutants blocked in 2,3-butanediol (and acetoin production) were unable to promote plant growth $(25,26)$.

Genes involved in the biosynthesis of Quorum Sensing (QS) molecules were also searched, such as Acyl-homoserine lactone (AHL) and homologous genes to the luxI/R family. A gene coding for a LuxR solo was found in strain UM270, not so in the rest of the pseudomonads analyzed. The solos are homologous to QS LuxR-type molecules able to respond to endogenous AHL and binding to low molecular weight molecules synthetized by the plant 
other than AHLs (27), thereby expanding their regulatory repertoire. Although, we could only identify a homologue of this family in UM270, it is possible that the rest of genomes also contain some members of the family, but not yet identified. For example, a subfamily of LuxR solos, named PsoR, was recently identified in the plant-associated bacteria Pseudomonas protegens strains Pf5 and CHA0 (28). Hence, further research is needed for determining new QS molecules and their mechanisms.

One common trait among these genomes was the presence of gene products involved in Quorum Quenching, such as AHL acylases and Homoserine dehydrogenases.

The presence of members from the Secretion Systems types I, II, III, IV and VI was also observed, which suggests a high level of rhizospheric competence and intense metabolic activity in this group of bacteria.

Of the genes that were found to exhibit variable patterns of presence and absence, those that encoded toxins were the most notable, including some Toxin-Antitoxin systems (TA), such as $\operatorname{vap} B C$, hig $A B$, relEK, relEB, hicAB and some unnamed TAs, widely reported among Proteobacteria, regulating normal physiological processes but also involved in pathogenicity of bacteria $(29,30)$. Importantly, genes involved in the synthesis of insecticidal toxins were detected in UM270, F113, PICF-7 and UW4 (Data not shown).

\section{Core-genome analysis}

The eight $P$. fluorescens strains core genome was analyzed as a measure of genomic intra-species variation. The core genome predicted contained 3,039 CDSs (Figure 1). This represents $56 \%$ of the predicted CDSs in UM270. The core genome covers from $51 \%$ to $58 \%$ of the SBW25 and A506 genomes, respectively. The data indicate high genomic variation in these fluorescent bacteria. By comparison, the related pan-genome of twelve Pseudomonas aeruginosa genomes contains a total of 5,316 core genes (10). However, distant species, such as Bacillus cereus, contained a smaller core genome $(3,030 \mathrm{CDSs})$ shared between twelve analyzed genomes (31).

The similarities between genomes with the UM270 strain were also analyzed. F113 shared more CDSs with UM270 (4,397), while UK4 was the most distantly related regarding the number of CDSs $(3,519)$ (Figure 2). This result agrees with the different habitats and ecological roles of each strain, being F113 a rhizospheric bacterium with biocontrol activities (32), similar to UM270; while UK4 is a biofilm former with no attributed plant-associated activity (15).

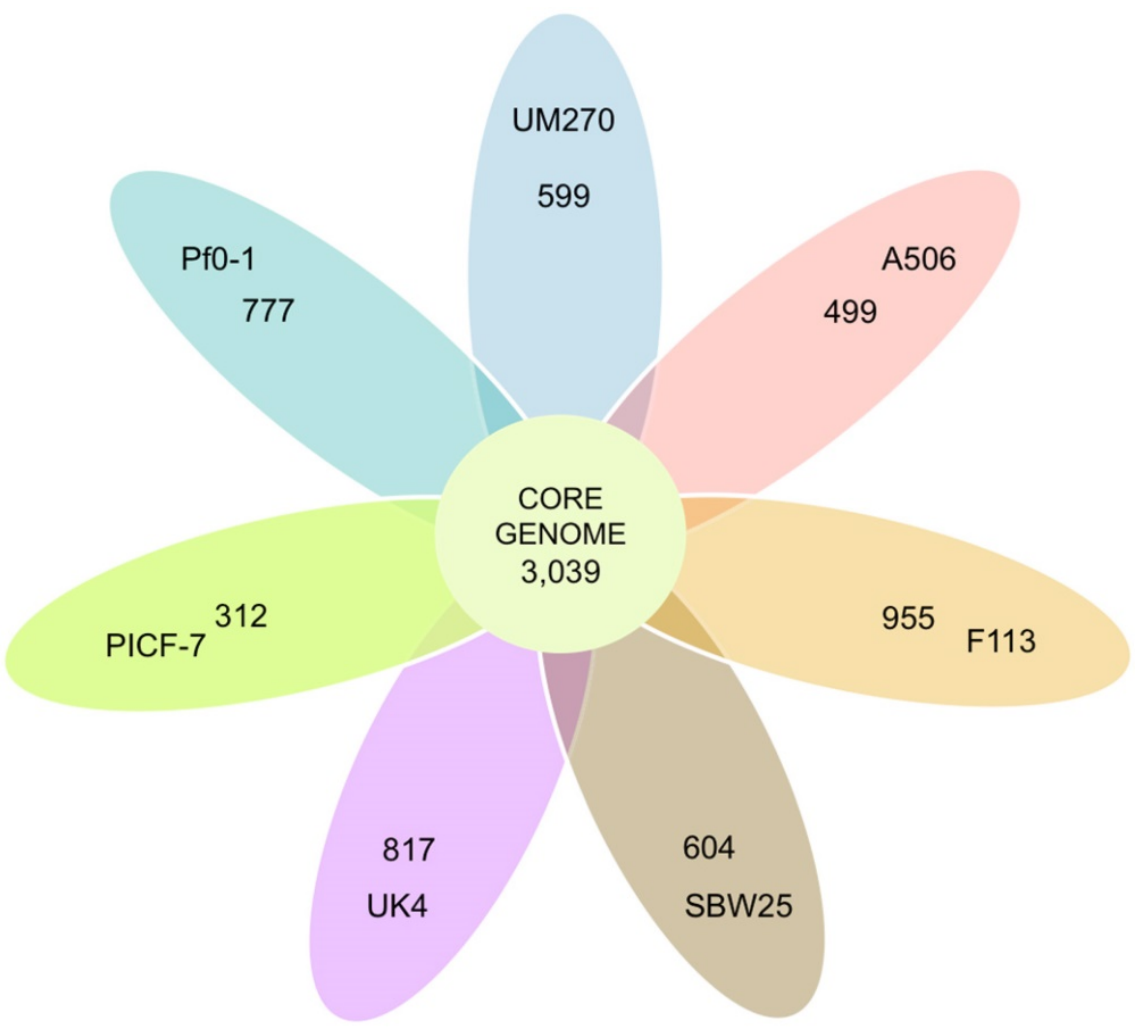

Figure 1. Venn diagram representing the core-genome of $P$. fluorescens. All shared and unique CDSs by the total of strains are presented in the circle. The ovals outside contain the number of CDSs that do not have homologs in any of the strains analyzed; that means unique predicted proteins. 


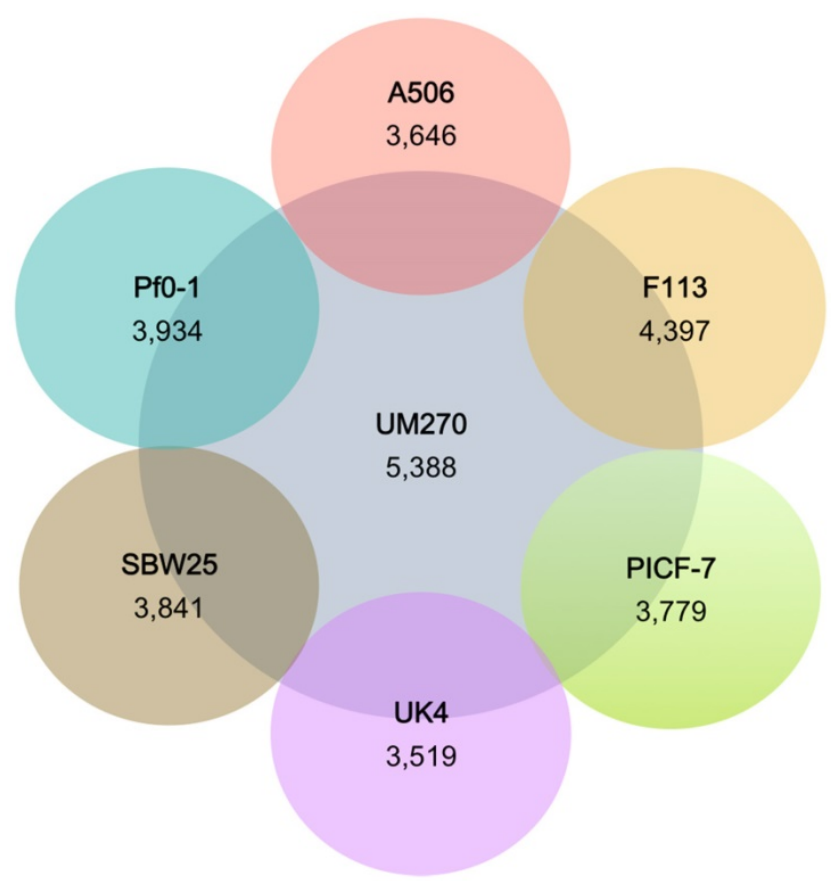

Figure 2. Number of predicted proteins shared between $P$. fluorescens complete genomes with the strain UM270. The inner circle shows the number of predicted proteins of UM270; whereas, external circles show the number of shared proteins with UM270.

\section{CDSs unique to UM270}

A total of 599 unique predicted CDSs in UM270 were identified. These protein-coding genes are not present in any of the rest of the pseudomonad strains surveyed in this study. From the total, 407 CDSs were of unknown function or encoded "hypothetical proteins." All these CDSs require further experimental analysis to discover putative roles in plant-bacteria interaction. Perhaps general transposon mutagenesis would help us discover non-reported gene functions. After this, we focused our analysis in the 192 CDSs (out of 599 unique UM270 genes) where we were able to assign a putative function or gene role. Among these, flagellar protein-coding genes were the major group (17 CDSs), which include biosynthetic proteins (FlhABPQR), regulatory flagellar protein (FleQ), motor switch (FliN), and structural basal-body rod proteins (FlgCDFG). A total of 15 transporters (including 11 ABC-transporters) were found. Fourteen regulatory proteins were also identified, from which eight belonged to transcriptional regulators. Some other frequent functions include proteases, hydrolases, secretion, activators, reductases and biosynthetic proteins.

From an extensive search of information about the unique proteins encoded in the genome of $P$. fluorescens UM270, a list of 17 genes (among many other) emerges form the genome comparison with the other strains, with activities that may be relevant in the rhizosphere, biocontrol and other plant-bacteria interactions. Among these genes, it is worth noting those involved in motility, secretion systems, sensorial activities and biofilm formation (See Table 2). Biofilm formation has been previously reported for the strain UM270, where its production might be playing an essential role in root attachment and rhizosphere colonization $(11,33)$. Biofilm formation has also been reported to be relevant for root colonization and plant protection, where bacteria $(B$. subtilis 6051) are able to produce antibiotic compounds (such as surfactin) that protect plants against pathogenic microorganisms (34).

Some candidate virulence factors present in UM270 genome were detected and found to perform the following putative functions: a 3-oxoacyl-[acyl-carrier-protein], catalase, capsule polysaccharide export, endoglucanase, cyclolysin secretion ATP-binding protein and diguanylate cyclase. In some species of the genus Pseudomonas these virulence factors are important for cell detoxification, resulting in host survival. Particularly, the presence of the O-antigen has been studied in gram-negative bacteria, mainly in $P$. aeruginosa as a potent virulence determinant, where it is highly immunogenic conferring a strong antibody response from the host (35). However, in a non-pathogenic bacterium such as $P$. fluorescens UM270, it would be interesting to assign a possible beneficial role during plant-bacteria interaction. 
Table 2. Biological activities of unique CDSs predicted in the genome of $P$. fluorescens UM270.

\begin{tabular}{|c|c|c|}
\hline $\begin{array}{l}\text { Predicted function } \\
\text { (Gene name) }\end{array}$ & Biological activity & Reference \\
\hline 3-oxoacyl-[acyl-carrier-protein] synthase, KASII & $\begin{array}{l}\text { Regulation of virulence factors. } \\
\text { Fatty acids biosynthesis. }\end{array}$ & $(40)$ \\
\hline Catalase & $\begin{array}{l}\text { Catalyzes decomposition of hydrogen peroxide. Essential for the bacteria to } \\
\text { prevent oxidative stress and survive in plants (colonization). }\end{array}$ & $(41)$ \\
\hline $\begin{array}{l}\text { Capsule polysaccharide export ATP-binding } \\
\text { protein }(c t r D)\end{array}$ & Implicated in virulence factors in bacteria and pathogens. & $(42)$ \\
\hline Endoglucanase D precursor & Catalyzes hydrolysis of $\beta-1,4$-glycosidic bonds of cellulose. & $(43)$ \\
\hline Epoxide hydrolase & $\begin{array}{l}\text { Enzymes important for detoxification of genotoxic compounds and } \\
\text { signaling control. }\end{array}$ & $(44)$ \\
\hline Isochorismatase & Biosynthesis of a group of siderophores. Phenazine biosynthesis. & $(45)$ \\
\hline Secretion protein HlyD family & Type I secretion system. Essential for RTX haemolytic toxin secretion. & $(46)$ \\
\hline NAD glycohydrolase; Halovibrin (hvnA) & Involved in mediation of signaling between bacteria-host in Vibrio fischeri. & $(36)$ \\
\hline $\begin{array}{l}\text { O-antigen biosynthesis protein } \\
\text { O-antigen export system permease protein } \mathrm{RfbD}\end{array}$ & $\begin{array}{l}\text { Important virulence determinant in Gram-negative bacteria. Also known as } \\
\text { endotoxins. }\end{array}$ & $(47)$ \\
\hline Oligopeptidase A & $\begin{array}{l}\text { Cleaves small peptides. Important for modification or interruption of } \\
\text { peptide messenger molecules against pathogens. }\end{array}$ & $(48)$ \\
\hline $\begin{array}{l}\text { Opine oxidase subunit B/ Hydrogen cyanide } \\
\text { synthase B }(h c n B)\end{array}$ & Virulence factor in P. aeruginosa. Antagonistic activity against pathogens. & $(49)(50)$ \\
\hline $\begin{array}{l}\text { Sensory box sensor histidine kinase/response } \\
\text { regulator }\end{array}$ & Important in signal transduction. Cellular receptors for signal molecules. & $(51)$ \\
\hline Signal transduction histidine kinase CheA & Two-component sensorial system. & $(38)$ \\
\hline Tauropine dehydrogenase & $\begin{array}{l}\text { Synthesis of octopines (Abrobacterium spp.). Found in tumors of crown gall } \\
\text { disease in plants. Quorum-sensing regulator. }\end{array}$ & $(52)$ \\
\hline $\begin{array}{l}\text { Transcriptional activator of acetoin } \\
\text { dehydrogenase. Operon AcoR }\end{array}$ & $\begin{array}{l}\text { Acetoin dehydrogenase is the immediate intermediary for the synthesis of } \\
\text { 2,3-butanediol. }\end{array}$ & $(53)$ \\
\hline $\begin{array}{l}\text { Diguanylate cyclase (DGC)/ phosphodiesterase } \\
\text { (GGDEF \& EAL domains) with PAS/PAC sensor }\end{array}$ & $\begin{array}{l}\text { DGC involved in biofilm formation in P. fluorescens Pf0-1. } \\
\text { PAS/PAC. Signaling domains for oxygen, redox potential, light and other } \\
\text { stimuli. }\end{array}$ & $(54)$ \\
\hline
\end{tabular}

A member of sensorial systems found in the UM270 genome includes halovibrin (hvnA), a histidine kinase two-component system (CheA) and sensory box regulators. Halovibrins (HvnA and HvnB) were identified in the symbiotic interaction between Vibrio fischeri and its host the squid Euprymna scolopes. HvnA and HvnB are secreted by $V$. fischeri and mediate symbiotic signaling during colonization of host tissues (36). On the other hand, histidine kinases allow bacteria, plants, and fungi to sense and respond to their environment, regulating a number of cellular responses such as osmoregulation, chemotaxis, sporulation and microbial pathogenesis (37). An homolog of the CheA histidine kinase of Thermotoga maritima (38) was also found in UM270. Phosphotransfer-mediated signaling pathways, involved in signal transduction, have been identified in Pseudomonas as the two-component GacS/GacA global regulatory system (39). All these genetic elements detected in UM270, but not in other analyzed strains here, unveil candidate genes for future analysis and potential roles for competence and colonization of the rhizosphere. If these candidate genes have essential roles during rhizosphere or root colonization, they might be helping UM270 strain to be well suited for other important roles, such as biocontrol of phytopathogens and direct plant growth-promotion, since all these multiple activities are linked together to benefit plant health $(11,21,33)$ aiming to a best effort to employ such microorganism in crop protection and sustainable improvement.

\section{Supplementary Material}

Supplementary figure 1.

http://www.jgenomics.com/v05p0091s1.pdf

\section{Acknowledgments}

GS thanks CONACYT-México (Project Number: 169346) and CIC-UMSNH (2016-2017) for financial support. JEHS received a scholarship from CONACYT-México and from ELAP-Canada. GMH received support from the Natural Sciences and Engineering Research Council of Canada (NSERC). Computer support by The Shared Hierarchical 


$\begin{array}{lrr}\text { Academic } & \text { Research Computing } & \text { Network } \\ \text { (SHARCNet: } & \text { http://www.sharcnet.ca/) } & \text { was } \\ \text { provided. } & & \end{array}$

\section{Competing Interests}

The authors have declared that no competing interest exists.

\section{References}

1. Cullen L, Mcclean S. Bacterial Adaptation during Chronic Respiratory Infections. Pathogens. 2015;4:66-89.

2. Loper JE, Hassan KA, Mavrodi D V, Davis EW, Lim CK, Shaffer BT, et al. Comparative genomics of plant-associated pseudomonas spp.: Insights into diversity and inheritance of traits involved in multitrophic interactions. PLoS Genet. 2012;8(7):1-27.

3. Santoyo G, Hernández-Pacheco C, Hernández-Salmerón J, Hernández-León R. The role of abiotic factors modulating the plant-microbe-soil interactions: Toward sustainable agriculture. A review. Spanish J Agric Res. 2017;15(1):1-15.

4. Martínez-García PM, Ruano-Rosa D, Schilirò E, Prieto P, Ramos C, Rodríguez-Palenzuela $\mathrm{P}$, et al. Complete genome sequence of Pseudomonas fluorescens strain PICF7, an indigenous root endophyte from olive (Olea europaea L.) and effective biocontrol agent against Verticillium dahliae. Stand Genomic Sci. 2015;10(10):1-7.

5. Haas D, Défago G. Biological control of soil-borne pathogens by fluorescent pseudomonads. Nat Rev Microbiol. 2005;3(4):307-19.

6. Weller DM. Pseudomonas biocontrol agents of soilborne pathogens: looking back over 30 years. Phytopathology. 2007;97(2):250-6.

7. Lugtenberg B, Kamilova F. Plant-growth-promoting rhizobacteria. Annu Rev Microbiol. 2009;63:541-56.

8. Feil H, Feil WS, Chain P, Larimer F, DiBartolo G, Copeland A, et al. Comparison of the complete genome sequences of Pseudomonas syringae pv. syringae B728a and pv. tomato DC3000. Proc Natl Acad Sci U S A. 2005;102(31):11064-9.

9. Silby MW, Cerdeño-Tárraga AM, Vernikos GS, Giddens SR, Jackson RW, Preston GM, et al. Genomic and genetic analyses of diversity and plant interactions of Pseudomonas fluorescens. Genome Biol. 2009;10(R51):1-16.

10. Ozer EA, Allen JP, Hauser AR Characterization of the core and accessory genomes of Pseudomonas aeruginosa using bioinformatic tools Spine and AGEnt. BMC Genomics. 2014;15(737):1-7.

11. Hernández-León R, Rojas-Solís $\mathrm{D}$, Contreras-Pérez $\mathrm{M}$, Orozco-Mosqueda M del C, Macías-Rodríguez LI, Reyes-de la Cruz H, et al. Characterization of the antifungal and plant growth-promoting effects of diffusible and volatile organic compounds produced by Pseudomonas fluorescens strains. Biol Control. 2015;81:83-92.

12. Hernández-Salmerón JE, Hernández-León R, Orozco-Mosqueda MDC, Valencia-Cantero E, Moreno-Hagelsieb G, Santoyo G. Draft Genome Sequence of the Biocontrol and Plant Growth-Promoting Rhizobacterium Pseudomonas fluorescens strain UM270. Stand Genomic Sci. 2016;11(5):1-7.

13. Miguel RN, Barret M, Morrisey JP, Germaine K, Francisco MG, Barahona $\mathrm{E}$, et al. Genome sequence of the biocontrol strain Pseudomonas fluorescens F113. J Bacteriol. 2012;194(5):1273-4.

14. Martínez-García PM, Ruano-Rosa D, Schilirò E, Prieto P, Ramos C, Rodríguez-Palenzuela $\mathrm{P}$, et al. Complete genome sequence of Pseudomonas fluorescens strain PICF7, an indigenous root endophyte from olive (Olea europaea L.) and effective biocontrol agent against Verticillium dahliae. Stand Genomic Sci. 2015;10:10.

15. Dueholm MS, Danielsen HN, Nielsen PH. Complete Genome Sequence of Pseudomonas sp. UK4, a Model Organism for Studies of Functional Amyloids in Pseudomonas. Genome Announc. 2014;2(5):e00898-14.

16. Duan J, Jiang W, Cheng Z, Heikkila JJ, Glick BR. The Complete Genome Sequence of the Plant Growth-Promoting Bacterium Pseudomonas sp. UW4. PLoS One. 2013;8(3):1-19.

17. Huson DH, Auch AF, Qi J, Schuster SC. MEGAN analysis of metagenomic data. Genome Res. 2007;17:377-86.

18. Edgar RC. Search and clustering orders of magnitude faster than BLAST. Bioinformatics. 2010;26(19):2460-1.

19. Ward N, Moreno-Hagelsieb G. Quickly finding orthologs as reciprocal best hits with BLAT, LAST, and UBLAST: How much do we miss? PLoS One. 2014;9(7):1-6.
20. Kloepper JW, Leong J, Teintze M, Schrotht MN. Pseudomonas Siderophores : A Mechanism Explaining Disease-Suppressive Soils. Curr Microbiol. 1980:4:317-20.

21. Santoyo G, Orozco-Mosqueda MDC, Govindappa M. Mechanisms of biocontrol and plant growth-promoting activity in soil bacterial species of Bacillus and Pseudomonas: a review. Biocontrol Sci Technol. 2012;22(8):855-72.

22. Ahmed E, Holmström SJM. Siderophores in environmental research: Roles and applications. Microb Biotechnol. 2014 May 1;7(3):196-208.

23. Kim Y, Cho J-Y, Kuk J-H, Moon J-H, Cho J-I, Kim Y-C, et al. Identification and antimicrobial activity of phenylacetic acid produced by Bacillus licheniformis isolated from fermented soybean, Chungkook-Jang. Curr Microbiol. 2004;48(4):312-7.

24. Glick BR. Modulation of plant ethylene levels by the bacterial enzyme ACC deaminase. FEMS Microbiol Lett. 2005;251:1-7.

25. Ryu C-M, Farag MA, Hu C-H, Reddy MS, Wei H-X, Paré PW, et al. Bacterial volatiles promote growth in Arabidopsis. Proc Natl Acad Sci U S A. 2003;100(8):4927-32.

26. Han SH, Lee SJ, Moon JH, Park KH, Yang KY, Cho BH, et al. GacS-dependent production of 2R, 3R-butanediol by Pseudomonas chlororaphis $\mathrm{O} 6$ is a major determinant for eliciting systemic resistance against Erwinia carotovora but not against Pseudomonas syringae pv. tabaci in tobacco. Mol Plant Microbe Interact. 2006;19(8):924-30.

27. Gonzalez JF, Venturi V. A novel widespread interkingdom signaling circuit. Cell. 2013;18(3):167-74.

28. Subramoni S, Gonzalez JF, Johnson A, Péchy-Tarr M, Rochat L, Paulsen I, et al. Bacterial subfamily of LuxR regulators that respond to plant compounds. Appl Environ Microbiol. 2011;77(13):4579-88.

29. Yamaguchi $Y$, Park J-H, Inouye M. Toxin-Antitoxin Systems in Bacteria and Archaea. Annu Rev Genet. 2011;45(1):61-79.

30. Wood TL, Wood TK. The HigB/HigA toxin/antitoxin system of Pseudomonas aeruginosa influences the virulence factors pyochelin, pyocyanin, and biofilm formation. Microbiologyopen. 2016;5(3):499-511.

31. Xu K, Yuan Z, Rayner S, Hu X. Genome comparison provides molecular insights into the phylogeny of the reassigned new genus Lysinibacillus. BMC Genomics. 2015;16(140):1-12

32. Redondo-Nieto M, Barret M, Morrissey J, Germaine K, Martínez-Granero F, Barahona E, et al. Genome sequence reveals that Pseudomonas fluorescens F113 possesses a large and diverse array of systems for rhizosphere function and host interaction. BMC Genomics. 2013;14(54):1-17.

33. Rojas-Solís D, Hernández-Pacheco CE, Santoyo G. Evaluation of Bacillus and Pseudomonas to colonize the rhizosphere and their effect on growth promotion in tomato (Physalis ixocarpa Brot. ex Horm.). Rev Chapingo Ser Hortic. 2016;22(1):45-57.

34. Bais HP, Fall R, Vivanco JM. Biocontrol of Bacillus subtilis against infection of Arabidopsis roots by Pseudomonas syringae is facilitated by biofilm formation and surfactin production. Plant Physiol. 2004;134:307-19.

35. Rocchetta HL, Burrows LL, Lam JS. Genetics of O-antigen biosynthesis in Pseudomonas aeruginosa. Microbiol Mol Biol Rev. 1999;63(3):523-53.

36. Stabb E V, Reich KA, Ruby EG. Vibrio fischeri genes hvnA and hvnB encode secreted NAD(+)-glycohydrolases. J Bacteriol. 2001;183(1):309-17.

37. Hoch JA. Two-component and phosphorelay signal transduction. Curr Opin Microbiol. 2000;3(2):165-70.

38. Bilwes AM, Alex LA, Crane BR, Simon MI. Structure of CheA, a signal-transducing histidine kinase. Cell. 1999;96(1):131-41.

39. Chancey ST, Wood DW, Pierson Iii ALS. Two-Component Transcriptional Regulation of N-Acyl-Homoserine Lactone Production in Pseudomonas aureofaciens. Appl Environ Microbiol. 1999;65(6):2294-9.

40. Taguchi F, Ogawa Y, Takeuchi K, Suzuki T, Toyoda K, Shiraishi T, et al. A homologue of the 3-oxoacyl-(acyl carrier protein) synthase III gene located in the glycosylation island of Pseudomonas syringae pv. tabaci regulates virulence factors via $\mathrm{N}$-acyl homoserine lactone and fatty acid synthesis. J Bacteriol. 2006;188(24):8376-84.

41. Guo M, Block A, Bryan CD, Becker DF, Alfano JR. Pseudomonas syringae catalases are collectively required for plant pathogenesis. J Bacteriol. 2012;194(18):5054-64.

42. Silver RP, Prior $K$, Nsahlai $C$, Wright LF. ABC transporters and the export of capsular polysaccharides from Gram-negative bacteria. Res Microbiol. 2001;152:357-64.

43. Bianchetti CM, Brumm P, Smith RW, Dyer K, Hura GL, Rutkoski TJ, et al. Structure, dynamics, and specificity of endoglucanase D from Clostridium cellulovorans. J Mol Biol. 2013;425(22):4267-85. 
44. Arand M, Cronin A, Adamska M, Oesch F. Epoxide hydrolases: structure, function, mechanism, and assay. Methods Enzymol. 2005;400:569-88.

45. Parsons JF, Calabrese K, Eisenstein E, Ladner JE. Structure and Mechanism of Pseudomonas aeruginosa PhzD, an Isochorismatase from the Phenazine Biosynthetic Pathway. Biochemistry. 2003;42(19):5684-93.

46. Linhartová I, Bumba L, Mašín J, Basler M, Osička R, Kamanová J, et al. RTX proteins: a highly diverse family secreted by a common mechanism. FEMS Microbiol Rev. 2010;34(6):1076-112.

47. Whitfield C, Trent MS. Biosynthesis and Export of Bacterial Lipopolysaccharides. Annu Rev Biochem. 2014;83:99-128.

48. Barrett AJ, Rawlings ND. Oligopeptidases, and the emergence of the prolyl oligopeptidase family. Biol Chem Hoppe Seyler. 1992;373(7):353-60.

49. Laville J, Blumer C, Von Schroetter C, Gaia V, Défago G, Keel C, et al. Characterization of the hcn $\mathrm{ABC}$ gene cluster encoding hydrogen cyanide synthase and anaerobic regulation by ANR in the strictly aerobic biocontrol agent Pseudomonas fluorescens CHA0. J Bacteriol. 1998;180(12):3187-96.

50. Blier AS, Vieillard J, Gerault E, Dagorn A, Varacavoudin T, Le Derf F, et al. Quantification of Pseudomonas aeruginosa hydrogen cyanide production by a polarographic approach. J Microbiol Methods. Elsevier B.V.; 2012;90(1):20-4.

51. Jung K, Fried L, Behr S, Heermann R. Histidine kinases and response regulators in networks. Curr Opin Microbiol. Elsevier Ltd; 2012;15(2):118-24.

52. de Kievit TR, Iglewski BH, Kievit TR De, Teresa R. MINIREVIEW Bacterial Quorum Sensing in Pathogenic Relationships. Infect Immun. 2000;68(9):4839-49.

53. Xiao Z, Xu P. Acetoin metabolism in bacteria. Crit Rev Microbiol. 2007;33(2):127-40.

54. Newell PD, Yoshioka S, Hvorecny KL, Monds RD, O'Toole GA. Systematic analysis of diguanylate cyclases that promote biofilm formation by Pseudomonas fluorescens Pf0-1. J Bacteriol. 2011;193(18):4685-98. 